\title{
Assessment of Wear Behavior on Treated AISI 630 Stainless Steel by Salt Bath Nitriding Process under Dry Sliding Conditions
}

\author{
D.Raguraman ${ }^{1}$, B.Ramakrishna Reddy ${ }^{2}$, N.Sateesh ${ }^{3}$, B.Ch.Nookaraju ${ }^{3}$, Aravind Deshini ${ }^{4}{ }^{*}$,Mansi Jagtap ${ }^{5}$, G.Phanindra Raja \\ Varma ${ }^{5}$, Ram Subbiah $^{3 *}$
}

${ }^{1}$ Faculty, Centre for Materials Engineering and Regenerative Medicine, Bharath Institute of Higher Education and Research, Chennai, Tamilnadu 600126, India.

${ }^{2}$ Faculty, Department of Basic sciences and Humanities, Gokaraju Rangaraju Institute of Engineering and Technology, Hyderabad 500090, India

${ }^{3}$ Faculty, Mechanical Engineering, Gokaraju Rangaraju Institute of Engineering and Technology, Hyderabad 500090, India ${ }^{4} \mathrm{PG}$ Student, Design for Manufacturing, Gokaraju Rangaraju Institute of Engineering and Technology, Hyderabad 500090, India ${ }^{5}$ UG Students, Mechanical Engineering, Gokaraju Rangaraju Institute of Engineering and Technology, Hyderabad 500090, India

\begin{abstract}
Grade 630 martensitic precipitation hardening stainless steel has a combination of high hardness and strength after suitable heat treatment. The great advantage of this grade is that they are usually supplied in the condition treated with the solution and then aged to achieve a sufficient high strength. Chosen for this research work, AISI 630 stainless steel samples were subjected to salt bath nitriding process. Three samples were chosen in the shape of tapered cylindrical shapes with diameter of $10 \mathrm{~mm}$ and length of $40 \mathrm{~mm}$. The specimens were subjected to 60 Minutes, 120 Minutes, 180 Minutes and named as SBN1, SBN2, SBN3 respectively. One untreated specimen is kept aside for the comparison purpose with the treated specimens. After the heat treatment process wear test were conducted by pin on disc wear test machine. Then the hardness test is carried out using the Rockwell hardness test. The microscopic images were taken using Scanning electron microscope. The results were compared and the best wear resistant material is chosen for the required application.
\end{abstract}

\section{Introduction}

Stainless steel is a group of iron alloys that contain at least about $11 \%$ chromium, a compound that prevents iron from rusting and also provides heat resistant properties [1-3]. The application includes in automotive parts like cam shafts, cam followers, injectors, bio medical implants, nuclear power plants, chemical and food industries. The several types of stainless steel include carbon $(0.03 \%$ to over $1.00 \%)$, nitrogen, silicon, aluminum, sulphur, nickel, copper, titanium, niobium, selenium and molybdenum [4-6]. The presence of chromium in the alloy forms a passive film that protects the base material from corrosion and can self-repair in the presence of oxygen, which accounts for stainless steels rust resistance. Corrosion resistance can be improved further by increasing the chromium content to more than $11 \%$, adding nickel at a rate of not less than $8 \%$, and adding molybdenum, which improves pitting resistance [7-11].

Grade 630 martensitic precipitation hardening stainless steel are composed of carbon $(0.07 \%)$, chromium $(10.5-18 \%)$ and iron. The significant advantage of this variety (and other precipitation hardening grades of stainless steel steel) is that they are usually supplied in the condition treated with the solution in which they are easy to process and can then be hardened against ageing to achieve a sufficiently high strength [12-16]. This ageing processing is so gentle that there is no discernible distortion. As a result, these estimates are well suited for the manufacture of long shafts that do not require re-dressing after heat treatment. This steel is typically supplied in a solution-treated state, allowing it to be machined [17-19]. Applications of this stainless steels include gears, bolts, and valve parts, die sets for plastic injection moulding, Pump shafts and boat propeller shafts with high strength, Parts of an engine. In general applications where corrosion resistance is required in addition to high strength or hardness [20-23]. Salt bath nitriding is a low-temperature heat treatment method used to achieve a specified hardness. This heat treatment is applied to low hardened steels to improve hardness and reduce uneven stress caused inside a steel material. This minimize treatment reduces the steel's brittleness and hardness while increasing its tensile strength. This boosts the steel's toughness at the expense of some hardness loss [23-25]. Almost all cutting tools require a firm cutting edge while also being strong and tough so that they do not shatter due to impact or fatigue.

\footnotetext{
* Corresponding author: author@e-mail.org
} 
Reheating the hardened steel to a temperature below the lower critical temperature, and then quenching it in an oil or salt solution to promote ductility on the material. Salt bath nitriding is usually performed in furnaces, equipped with a bath containing salts enriched with nitrogen. The process is done in a closed atmosphere to prevent surface oxidation during the process and usually carried out at higher temperatures [12-14].

\section{Experimental procedure:}

\subsection{Material composition:}

Chosen for this research work, AISI 630 Grade precipitation hardened stainless steel with less proportion of carbon were subjected to salt bath nitriding process in order to maintain a stable relationship with hardness and ductility. The composition for the material is chosen as Chromium-15.8\%, Nickel-3.5\%, Carbon-0.07\%, Manganese- $0.51 \%$, Phosphorous- $0.03 \%$, Sullphur$0.008 \%$, Silicon- $0.5 \%$, Copper- $3.5 \%$, Nb+Ta- $0.4 \%$, IronRemaining\%.

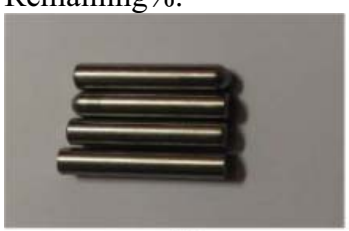

(a)

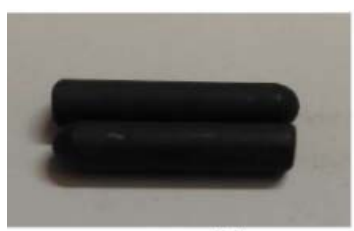

(c)

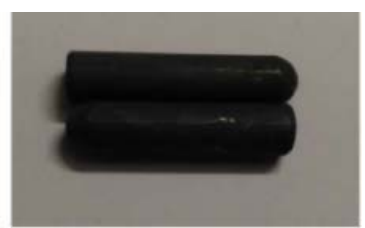

(b)

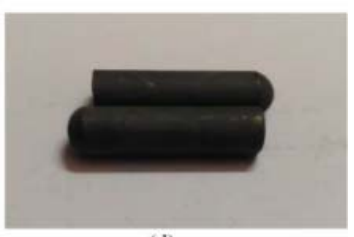

(d)
Fig.1. AISI 630 stainless steel specimens

\subsection{Treatments and wear test:}

AISI 630 stainless steel was cut into small cylindrical specimens $40 \mathrm{~mm}$ long and $10 \mathrm{~mm}$ in diameter using an electrical discharge machining process. The size of the disc turned out to be $100 \mathrm{~mm}$ in diameter and $10 \mathrm{~mm}$ thick. Three pins of the same grade were exposed to salt bath nitriding process to $1 \mathrm{hr}, 2 \mathrm{hr}$ and $3 \mathrm{hr}$ respectively as shown in Fig 1 (b-d). One untreated specimen as shown in Fig 2.a is kept for comparison of results with nitrided specimen. Before all procedures samples were cleaned and dried, being careful without any finger contact. Before nitriding, the specimens were undergone with sandblasting and etching in $15 \%$ sulfuric acid for 20 minutes.

Wear tests were performed on the salt bath nitrided specimens using a pin-on-disc machine as shown in Fig 2. Samples were thoroughly cleaned with acetone prior to testing and the disc material was surface hardened to salt bath nitriding process to the saturated limit. The experiments were carried out on a pin on a disc machine, and the subsequent variables were changed. The pin rotates on the disc after the load is applied, and the sliding distances were kept constant as $30 \mathrm{~mm}$. The wear loss values were determined by the amount of material detached from the pin. A load of $10 \mathrm{~N}$ was applied during the wear test while maintaining a constant rotational speed of $1000 \mathrm{rpm}$, keeping the time 2 minutes as constant.

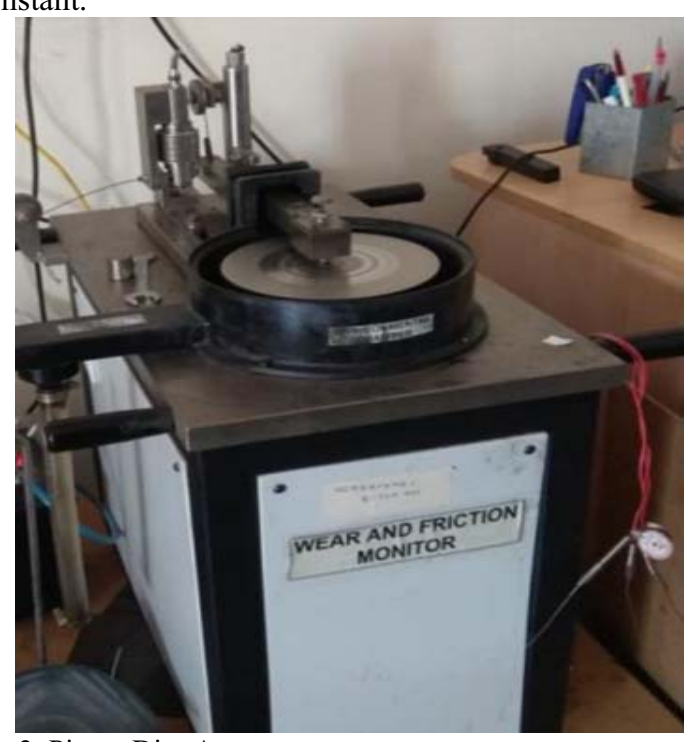

Fig.2. Pin on Disc Apparatus

The wear loss was calculated using the difference between the specimen's weight before it was tested and after the wear test. Microscopic observations were made using SEMs (Scanning Electron Microscopes). Microstructure analysis was used to examine the surface morphology of AISI630 stainless steel. The technical characteristics of the scanning electron microscope are as follows: Nikon make with magnification with secondary electrons from $10 \mathrm{x}$ to $50,000 \mathrm{x}$, backscattered electrons from $10 \mathrm{x}$ to $35,000 \mathrm{x}$, works with accelerating voltage, secondary electrons; $5 \mathrm{kV}, 10 \mathrm{kV}, 15 \mathrm{kV}$ (3 steps) Backscattered image; $10 \mathrm{kV}, 15 \mathrm{kV}$ (2 steps), electronic Small gun with cartridge integrating the filament, Maximum sample size Diameter $80 \mathrm{~mm}$, height $60 \mathrm{~mm}$ Developed image $645 \times 485,1285 \times 965$ pixels.

\section{Results and Discussions:}

The hardness of the samples was determined using a Rockwell hardness tester with a load of $150 \mathrm{~kg}$ with a time period of 30 seconds. Used hardness testing machine type TRSN manufactured by Universal Test Machines, test load range from 60 to $150 \mathrm{kgf}$, with a maximum test height of $225 \mathrm{~mm}$, a throat depth of $135 \mathrm{~mm}$, a total equipment height of $628 \mathrm{~mm}$, a total weight of $65 \mathrm{~kg}$, base dimensions $455 \times 270 \mathrm{~mm}$. Untreated AISI 630 stainless steel was found to have a hardness of $27 \mathrm{H}_{\mathrm{RC}}$. Hardness for SBN1, SBN2, and SBN3 was observed to be $29 \mathrm{H}_{\mathrm{RC}}, 33 \mathrm{H}_{\mathrm{RC}}$ and $37 \mathrm{H}_{\mathrm{RC}}$ respectively. 


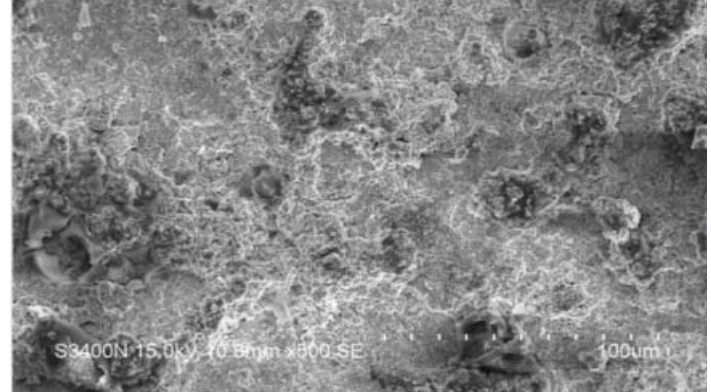

Fig.3. SEM Image of Untreated AISI 630 Specimen

The residual layer indicates the base metal, whereas the white layer reveals material peeling off during wear tests. During the wear test, there was huge loss of material in the untreated specimen. This is because of high ductility in the material. Also due to load applied on the material as shown in Fig 3.

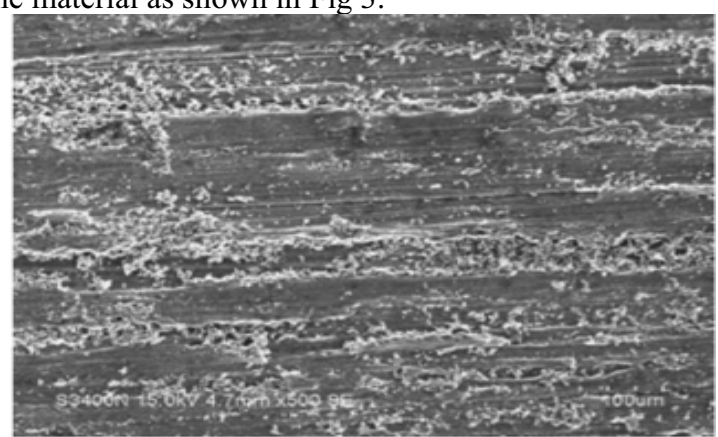

Fig.4. SEM Image of SBN1 specimen at 60 Minutes

The sample was subjected to a salt bath nitriding process for 60 minutes, which resulted in less material loss. The specimens were enlarged to $100 \mu \mathrm{m}$, revealing the generation of a scattered layer of chromium and nitrogen that shields the sample from adhesive and abrasive wear. As there was a change of material phase to expanded austenite compared to untreated sample, the material's wear resistance was improved as shown in the Fig.4.

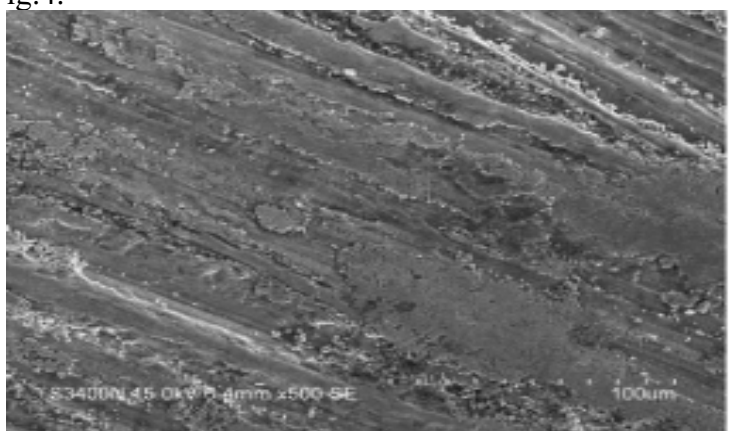

Fig.5. SEM Image of SBN2 specimen at 120 Minutes

It was noted that the sample treated for 120 minutes had very little wear loss compared to the sample treated for 60 minutes. This is due to the increased treatment time. On the surface of the material, an extremely strong hardened surface is generated, which protects it from external wear. When compared to the grain structure of the sample treated for 60 minutes, the grain structure of the sample treated for 120 minutes was finer, and cracks were reduced. The increase of nitrogen content, determines the precipitation of chromium carbide on the surface of the specimen as shown in Fig.5.

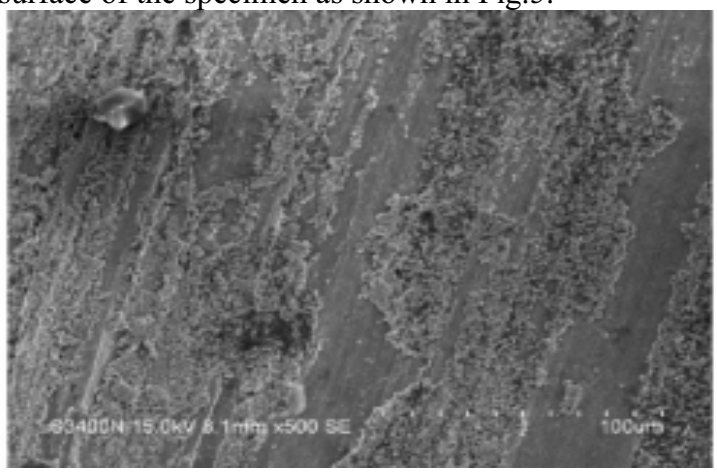

Fig.6: SEM Image of SBN3 specimen at 180 Minutes

Components that have been salt bath nitrided have great sliding and running properties as well as increased wear resistance. The presence of iron nitride compounds generated at the compound layer enhances wear resistance, lubricity, and fatigue strength. Both of these zones are metallurgically distinct, and each provides engineering properties such as anti galling, anti seizing, and a reduced tendency for fretting corrosion. As a result, for the sample treated for $180 \mathrm{~min}$, the grain structure in the SEM image at $100 \mu \mathrm{m}$ magnification became fine compared to the grain structure of the untreated sample. This zone is known as a compound zone, and it is characterized by the correct diffusion of nitrogen and chromium atoms on the surface, which ensures good wear resistance as shown in Fig 6.

\section{Conclusion}

Although many researchers have conducted research on the nitriding of stainless steels, there is little work published on nitriding of AISI 630 Stainless steels. On consideration of the need for further study, this research attempt was made to investigate to find out the effect of salt bath nitriding process on the microstructure, hardness and wear properties of AISI 630 stainless steels. The comparison is made between the nitrided and untreated specimens. The specimen which improves the wear resistance and increases the life of material is chosen for the required application. The main conclusions were drawn from the above experimental works:

(i) As a result of the wear test, it was found that the specimen treated to 180 Minutes have improved the wear resistance stabilizing the hardness and ductility.

(ii) After salt bath nitriding process, the material phase changes from martensite to expanded austenite were obtained. The combined nitrogen and chromium is deposited into chromium nitride, improving the hardness of the AISI 630 stainless steel material. 
(iii) Volumetric wear losses of the specimens were found to be $9.76 \times 10{ }^{-4} \mathrm{~cm}^{3}, 8.024 \times 10-^{4} \mathrm{~cm}^{3}$, $7.01 \times 10-^{4} \mathrm{~cm}^{3}$ and $6.99 \times 10-{ }^{4} \mathrm{~cm}^{3}$, respectively.

(iv) According to the electron microscope results, the treated sample at 180 minutes has good wear resistance, stabilized with good ductility and brittleness. As a result, the sample is suitable for commercial use.

\section{References}

1. R.V. Pushkarev, N.I. Fainer, H. Katsui, Mater.Des.J.E 137, 1 (2018)

2. A.P. García-Mendoza, G. Vargas-Gutiérrez, J. López-Cuevas, Surf. Coat.Tech.J.E 353, 1 (2018).

3. F. Bottoli, M.S. Jellesen, T.L. Christiansen, G. Winther, M.A.J. Somers, App.Sur.Sci.J.E 431, 24 (2018)

4. N. Chen, G. Ma, W. Zhu, A. Godfrey, Z. Shen, G. Wu, X. Huang, Mat. Sci. Eng. A.J. E 759, 82 (2019).

5. J.W. Zhang, L.T. Lu, K. Shiozawa, W.N. Zhou, W.H. Zhang, Fatigue.J.E 33, 880 (2011).

6. M.G. Shahri, M. Salehi, S.R. Hosseini, M. Naderi, Surf. Coat Tech.J. E 310, 44 (2017).

7. M.Mamatha Gandhi, Animesh Bain, $P$ Rohith, R. Srilatha, Ram Subbiah, Structure and Topography Modifications of Treated AISI 316LN Stainless Steel Surfaces after Friction in Dry Sliding Contact by Case Hardening Process (EDP Sciences, Hyderabad, 2020)

8. K. Ramya Sree, G. Keerthi Reddy, K. Aishwarya, E. Nirmala Devi, Ram. Subbiah, New Insights of Wear Behavior Analysis on Low Temperature Treated AISI 253MA Stainless steel Material by Gas Nitriding Process (EDP Sciences, Hyderabad, 2020)

9. A Rohit Sai Krishna, B Vamshi Krishna, D Harshith, T Sashank, Ram Subbiah, Investigation of Mechanical Properties of AISI 316 Stainless Steel by Carbonitriding Process (EDP Sciences, Hyderabad, 2020)

10. Shivani Koppula, Aakula Rajkumar, Siram Hari Krishna, Reddi Sai Prudhvi, S. Aparna,Ram Subbiah, Improving the Mechanical Properties of AISI 2205 Duplex Stainless Steel by Cryogenic Treatment Process (EDP Sciences, Hyderabad, 2020)

11. Lakshmi Deepak Tadepalli, Ananda Mithra Gosala, Lokesh Kondamuru, Sai Chandra Bairi, A. Anitha Lakshmi, Ram Subbiah, Assessment of Properties on AISI430 Ferritic Stainless Steel by Nitriding process (EDP Sciences, Hyderabad, 2020)

12. Gandla Lakshmi Prasanna, G. Keerthi Reddy, Ram Subbiah, Evaluation of properties of AISI 431 Grade Stainless Steel by Vacuum Annealing Process (EDP Sciences, Hyderabad, 2020)
13. Gandla Lakshmi Prasanna, J Saranya, Ram Subbiah, Assessment of AISI 431Grade Stainless Steel properties by Vacuum Tempering Process (EDP Sciences, Hyderabad, 2020)

14. Manne Vamshi, J. Saranya, Ram Subbiah, Improvement of Characteristics of AISI 310 Grade Stainless Steel Material By Carburizing (EDP Sciences, Hyderabad, 2020)

15. ManneVamshi, AnimeshBain, M.Sreekanth, Ra $\mathrm{m}$ Subbiah, Wear Characteristics of AISI 310 Grade Stainless Steel Material by Carbonitriding Process (EDP Sciences, Hyderabad, 2020)

16. Ram.Subbiah, Md.Rahel, A.Sravika R.Ambika, A.Srujana, E.Navya, Investigation on Microstructure and Mechanical Properties of P91 Alloy Steel Treated With Normalizing Process - A Review (Materials Today: Proceedings, Hyderabad, 2019)

17. A. Rohit Sai Krishna, B. Vamshi Krishna, T. Sashank, D. Harshith, Ram Subbiah, Influence and assessment of mechanical properties on treated P91 steel with normalizing processes (Materials Today: Proceedings, Hyderabad, 2020)

18. K. Manjith Srinivas, S. Bharath, P. N. V. Krishna Chaitanya, M. Pramod, Ram Subbiah, Improving tribological properties of P91 steels through carburizing process (Materials Today: Proceedings, Hyderabad, 2020)

19. B.Chaitanya kumar, P.Sri Charan, Kanishkar Jayakumar, D.Alankrutha, G.Sindhu, Ram

Subbiah, Assessment of wear properties on low temperature molten salt bath nitriding on austenitic stainless steel (Materials Today: Proceedings, Hyderabad, 2020)

20. T.LakshmiDeepak,G.AnandaMithra,

K. Lokesh, B. Sai Chandra, Ram Subbiah, Stability of expanded austenite by gas nitriding process on austenitic stainless steel material under low temperature conditions (Materials Today: Proceedings, Hyderabad, 2020)

21. Nirmala Devi,

G.Chitra.S, Selvasekarapandian.S. Premalatha, M. Monisha, S. Saranya.J, Ionics.J.E 23, 2337 (2017)

22. Patel.S, Rana.R.S, Singh.S.K, Study on mechanical properties of environment friendly Aluminium E-waste Composite with Fly ash and E-glass fiber (Materials Today: Proceedings, Hyderabad, 2017)

23. Prasad.K.S, Gupta.A.K, Singh.Y, Singh.S.K, Materi Eng and Perform.J.E 25, 5411 (2016)

24. Ganesh.R, Subbiah.R, Chandrasekaran.K, Dry Sliding Wear Behavior of Powder Metallurgy Aluminium Matrix Composite (Materials Today: Proceedings, Hyderabad, 2015)

25. Dhanalaxmi.B, Apparao Naidu.G, Anuradha, K, Adaptive PSO based association rule mining technique for software defect classification 
using ANN (Procedia Computer Science,

Hyderabad, 2015) 